\title{
Mix Concrete: Combining the Composition to Create New Surface of Architectural Building
}

\author{
Tria Amalia Ningsih ${ }^{1, *}$, Dalhar Susanto ${ }^{1}$, and Intan CHairunnisa ${ }^{1}$ \\ ${ }^{1}$ Department of Architecture, Faculty of Engineering, Universitas Indonesia
}

\begin{abstract}
Concrete has been transfigured from the object of mass production at twentieth century to advancing technology of building a new formation of contemporary architectural design. Concrete has evolved in ranging aggregate particles, to push the boundary the concept of reinforcing concrete with high-performance quality the thinness or elasticity. There are several conditions of concrete construction based on assembling this material towards architectural buildings. In the architectural practice, the issue of structure underlines the combination of concrete system which resists the tensile strength. Concrete also reflects on surfaces of architectural elements and potentially reshaped as a vehicle for sculptural form. Mixed concrete is a preliminary idea of mixing concrete composition with other materials such as gravel, ceramic and plastic which then discovers different form or texture. The forms of expression which have emerged alongside the technical developments reflect aesthetic value with various surfaces. This exploration is a part of learning activities in building technology class which aims at directing students to utilize concrete through mixing technique. It is developed in order to create a sustainability process of concrete and discuss the possibilities of future environmental impact by using concrete. Reshaping the visible face of concrete reveals the astonishing achievement of architecture.
\end{abstract}

\section{Introduction}

Concrete has retained an emblematic character. Its use is still associated with issues pertaining to the relation between architecture and technology ${ }^{[1]}$. In Modernism era, concrete helped designers answer the challenge of technology through its shaping power, its dynamism, and capacity to produces fascinating objects and systems. It is also a radical shift in the conceptualization and usage of concrete by a community of engineers and builders. For example, Hennebique system appeared as the transformation of the reinforced concrete into a fullservice building material with a set of competing structural system. Furthermore, concrete enables to free itself from the idea of stiff constructions. While masonry only represents a traditional construction, concrete can be adapted by the architecture with sufficient form. Moreover, concrete gives the general evolution of technology as well as increasingly hybridized type of concrete. The idea of combining concrete materials with others enhances the abilities in the formation of component on the architectural building.

Meanwhile, concrete could be used without the exportation of machinery or capital but simply of (relatively immaterial) technical expertise ${ }^{[2]}$. Its use is flexible and durable to form by binding sand, stone and other aggregates within the manufacture of liquid cement. Thus, the aim of this study is to identify the possibilities of concrete utilization by mixing the concrete with other materials using the manual technique. This knowledge is to motivate and encourage students to use concrete in sustainable approach. It forms the ethics with aesthetic value in architectural building.

\section{Advance in concrete technology as the face of architecture}

The development of concrete has become a technological artefact which shows a new way of creating architectural objects. Prior to concrete, people used to build it manually, making by bricks one on top of the other to set up walls, but now it can be moulded and united. Furthermore, the creation of form is also not just as flat field that only has two sides like a wall in general, but it can creates arches or dome that can be constructed in accordance with the desired mould. Clearly, concrete enables architecture to position itself, suggesting the idea of journey made possible by the flexibility of concrete with its technology.

Moreover, the form which is considered difficult in its manufacture such as wide span or cantilever, can be finished with combining concrete and steel construction. One of the first concrete capabilities shown in the world of architecture is The Falling Water by Frank Lloyd Wright. The building consisted of horizontal reinforce concrete formed transversely and overlapping with other

\footnotetext{
Corresponding author: tria.amalianingsih@gmail.com
} 
concrete forms, then, it is separated by masses of local sand stone. In its design, concrete was considered as the ideal medium in carrying out its constructions, although the use of concrete and stone is a less common material in designing the house but the design shows that concrete can be thrown in any form and its nature is really elastic. Moreover, concrete has advantages in its tensile strength in accordance with its incorporation with steel, so that the cantilever form becomes possible to create. This perfect blending of nature with the universal materials, stone and concrete, is a great performance indeed $^{[3]}$.

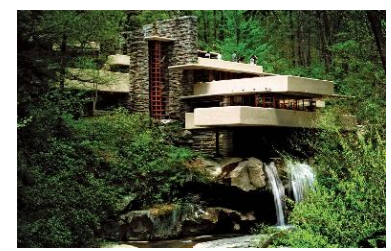

Fig. 1. Falling Water by Frank L Wright

This development of concrete is then continued by trying to create concrete as a material that has been completed without the need to be re-coated. This is to show that of the natural beauty of concrete not only as a structural element, but also as beauty properties in its application. Many designers compete to compose concrete as the end result of the building by showing the various surfaces that can be produced with this material. Once, they tried to mix the concrete with other materials to give a different texture in the face of the building.

Furthermore, utilizing a concrete as a main material of the house gives benefits impact to surrounding. It becomes a place for living organism to grow without disturbing the structural functions. It creates a sustainable environment that has capable to adapt and create a better ecosystem.

An Indonesian architect, Andramatin, is an architect who manages to explore concrete in his design. Concrete is not only raised as a part of the building structure but also as the surface of a building facade. In the design of AM house, he uses concrete in both outside and inside of the building and let the house to blend with the surrounding vegetation. He also allows the moss to grow in the façade of the building which does not affect the structural technology. He believed, in addition to provide a beauty, concrete is a low maintained material that capable to engage a friendly environment. There is strong connection between inside and outside that is envisage to bring nature closer with its residents ${ }^{[4]}$.

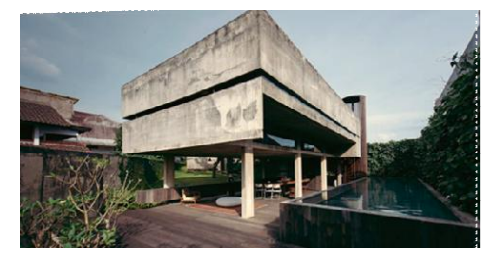

Fig. 2. AM House by Andramatin

These advances bring the realization that architecture becomes a monument of public significant. It creates a new face of architecture where concrete as the main actor of the design. Transforming the properties of materials into visually aesthetic building creates a reformed perspective for both the material and sustainable architecture.

\subsection{The Origin of Concrete}

The terms concrete is the assembly of coarse material such as stone, gravel, or other aggregates, and mixed with sand. It is added with a binder and water that creates forms a hard artificial stone. It has been created from a mixture of cement, aggregates and water with any other mixtures which may be added to modify the placing and curing processes or the ultimate physical properties $^{[5]}$. It takes the shape of the mould or formwork. Each type of concrete has its own properties and has been exploited in many different wants by architects and engineers ${ }^{[6]}$. It can be reinforced or prestressed by combining other material such as stone, wood or steel. The material becomes solid when it is hardened, utilized as load-bearing wall or lightweight, thermal insulating material, depending on the usage of the aggregate.

Additionally, Aggregates properties have significant effects on the physical properties of the concrete mixes and hardened concrete, including crushing strength, size, grading, and shape. A good-quality aggregate has various advantages over surrounding, binding, hydrated cement, which are normally a higher strength; better durability; no change in volume due to moisture, hence a reduction in the shrinkage mass of concrete; and absorb the heat of hydration and hence exercises and attenuating effect during the curing process ${ }^{[7]}$. This process brings a sustainability way for the concrete industry, from grinding the limestone until it is ready to use as liquid cement.

\subsection{The usage of sustainable concrete}

Generally, the usage of concrete was just focused on two major issues, between the structural and non-structural uses. This significance is now changed because the evolution of technology that is increasingly hybridized. These types of concrete are being developed daily ${ }^{[1]}$. Its use originates from its functions as a structural element due to its ability in strength and tensile, changed into a space shaper in the design strategy. Now, the sustainable agendas have influenced the use of concrete in the creation of architectural buildings.

There are advantages by using a sustainable concrete, it has reduced maintenance and energy cost in the production. It is also minimising the fuel needed for heavily loading trucks. Furthermore, in the term of insulating regulation, concrete has reduction in building system $^{[12]}$. Thus, concrete has competed as environmentally material that has certain good qualities including durability, friendly and a higher productivity in term of construction.

\subsubsection{Concrete as Structure}

One way of applying concrete in terms of structure is with the series of dichotomies that are substantial with the material itself. Dichotomy is, so to speak, built from 
the very beginning into the assembly of iron rods and concrete but also into concrete itself, being a mixture of solid substance and water ${ }^{[2]}$. With this process, the design of the component takes into account of the fundamental structural requirements between compression and tension, which had led since the origins of construction to the parallel development of masonry and wooden components.

Reinforced concrete is a great example of loadbearing structure that characterizes today's architecture. In construction, concrete is used with a variety of possibilities because the material is inexpensive and quick to build compared to other materials. They are certain criteria to put concrete as a sustainable material. Reinforced concrete has simply become the twentieth century's building material of choice and the symbol of unbridled building activity ${ }^{[7]}$.

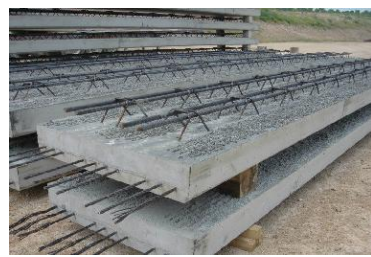

Fig. 3. Sample of Reinforce concrete

\subsubsection{Concrete as Surface}

Concrete can also serve as a surface in the formation of architecture as a contemporary method of construction. It is the concrete as the main material that rounded the form aesthetically. Because of its appearance as a surface of the building, the end result of the concrete application has also been developed. The application is considered from the texture, colour, durability, until its addition of other materials in the mixture, making the sustainable technology developed quite rapidly. These developments produce concrete as a material that can be applied both within and outside of architectural buildings.

There are several exposed concretes which visualize the concrete surface. Deplazes ${ }^{[7]}$ distinguished between two types of exposed concrete depending on the whether the outermost, the thin layer of cement directly adjacent to the surface of the formwork is retained or removed. On the cement "skin" retained, the pattern of the formwork and the formwork ties determine the appearance with the joint can be dealt with in various ways, such as butt joint and open joint. On the other hand, the "skin" removed remains with the thin layer of cement, the outermost, can be modified or completely removed by using various manual or technical treatments. The surface layer is worked or treated to reveal the aggregate.

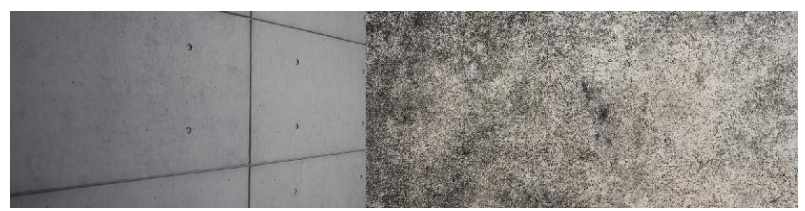

Fig. 4. The retaining walls (left); the texture of outermost concrete (right)
Furthermore, the quality of visual concrete is heavily dependent on the formwork as the finishes will be mirrored in the concrete surface. Smooth concrete is made by in direct as-cast concrete, called in-situ concrete, with hard shiny, non-absorbent formwork materials, such as steel, glass-fibre reinforce polyester (GRP) or plastic-coated plywood so that it can gives smooth surfaces ${ }^{[5]}$. The skin of the concrete enclosed its structure. There are developments of sophisticated techniques of cast-in-place concrete construction in the making by using certain moulding. Based on this system, the fundamental constraints relate to the process of exposed concrete which are the mould, the mix, and the workmanship. The originality of the technique lays in the exploration of the aesthetic potential of repeatable elements, where the structure and envelope were moulded into one and the same form, then built in a single operation ${ }^{[8]}$.

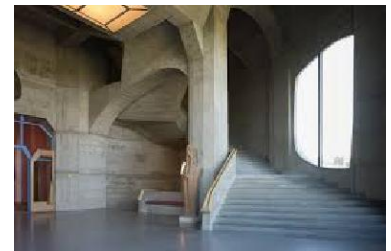

Fig. 5. The smooth concrete using cast-in-place technique by Rudolf Stainer

The exposure of the coarse aggregate in concrete, by removal of the smooth surface layer formed in contact with the formwork, produces a concrete with a more durable finish and better weathering characteristics, which is frequently aesthetically more pleasing ${ }^{[5]}$. This technique gives additional opportunities for the uniform placement of the aggregate. The aesthetic possibilities of exposed concrete, as revealed as rough concrete, have been developed in concrete that sustains and encourages the living organism grow on the surface of facades. By composing the three layers on the top of the structural elements, the concrete provides ecological, thermal and aesthetic advantages for the building ${ }^{[13]}$. Its results in the rough concrete emphasized as the soft-scape which created the character of architecture.

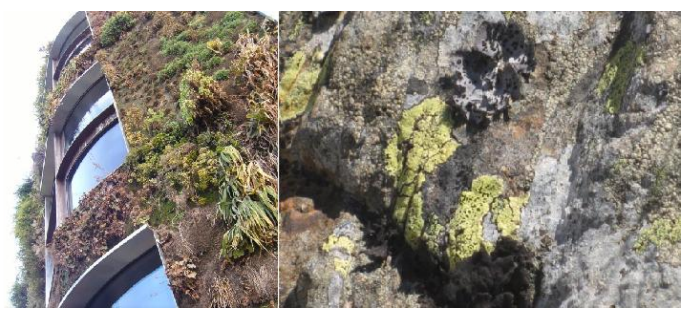

Fig. 6. Universitat Politecnica de Catalunya, BarcelonaTech.

\subsubsection{Concrete as Sculpture}

One of the advantages of concrete that has a liquid form at the beginning of manufacture, makes concrete to have the abilities to be built as sculpture. There is a consideration on the new possibilities of concrete, with a particular emphasis on "surface treatment and sculpture" and a certain passion for parabolic arches ${ }^{[2]}$. The changing perspective of concrete use based on producing component of concrete in architectural innovation. 
One of successful innovation in concrete that is used mostly as sculpturing architectural elements is feroconcrete. It is a thin construction element with thickness around $10-25 \mathrm{~mm}$ and uses rich cement without coarse aggregate in mixture. It consisted with one or more layers of continuous or small diameter steel wire or weld mesh netting ${ }^{[9]}$. It doesn't need skilled labour for casting and formworks and doesn't crack because using the wire mesh reinforcement below the surface. It is being explored as building materials substituting stone, brick, RCC, steel, pre-stressed concrete and timber and also as structural components and other application including window, door frames and shutter ${ }^{[10]}$. Clearly, ferroconcrete can be fabricated into any desired form or structural configuration that is generally not possible with standard materials.

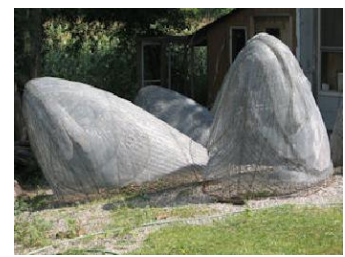

Fig. 7. Ferro-concrete technique

In this modern era, concrete played a leading role in developing the creation of building systems. It has allowed us to create the mass production of industrial, commercial, and residential structures. The systems emerged from the encounter between technical and ingenuity and entrepreneurial savvy ${ }^{[2]}$. The system is the invention of using concrete approaching sustainable concept, from less wasted cast-concrete until a highquality surface from combining aggregates and living organism. These creations push the boundaries of concrete that have functions as beautiful as the environmentally invention.

\section{Methodologies}

The goal for experimental research is to achieve comparability among the units in each treatment group, such comparability is more precisely established in experimental research through random assignment ${ }^{[11]}$. In this case, this paper seeks to ascertain or establish effective comparability in mixing concrete across many variables. The experiments use different materials as the mixture of concrete. There are several techniques that implied in the process, moulding, adding, and dyeing the materials. Each process holds similar treatments in order to compose the concrete. This experiment also shows the ability of concrete as a surface, where concrete plays a furnishing material that can provide aesthetic value for architectural buildings and further impact in environment.

On Architectural construction, in order to see the quality of the aesthetic in the material can be seen from the senses. Vision is obviously something like a pictorial memory of earlier physical-sensual experiences which responds to surface stimuli ${ }^{[7]}$. A dimension in space can be confirmed by touching the texture on the wall surface or seeing the colour resulting from the fall of light on the material. So this sensual experience can be understood as the aesthetic comprehension of a material surface. Furthermore, it continues with analysing the possibilities of creating new form of sustainable concrete in order to see further implication of developing ecological layer of concrete.

\section{Study case}

This exploration started with preparing the concrete as the basic materials for the mixed concrete. The composition for all the cast of concrete used the same aggregate in the initial phase, cement, sand and water. Then it is continued with different treatment and technique based on materials that is synthesized with the concrete. The first technique, moulding, is printing a particular shape from other material or object at the top of surface while the concrete is still wet. When the concrete became hardened, the object was removed from the concrete. Adding, the second technique is using other materials as other aggregates that are inserted, whilst living its top surface visible. The third one is dyeing which is combining concrete with other materials to create a certain colour. All the additional materials were combined with wet cement that was printed on a plastic container to be removed after the cement dried.

Table 1. The process of mix concrete with other materials.

\begin{tabular}{|c|c|c|}
\hline Material & Technique & Process \\
\hline Plastic & moulding & $\begin{array}{l}\text { Plastic is } \\
\text { placed at the } \\
\text { top of surface } \\
\text { of concrete. }\end{array}$ \\
\hline $\begin{array}{l}\text { Lid of jar } \\
\text { (plastic) }\end{array}$ & moulding & $\begin{array}{l}\text { Plastic is } \\
\text { placed at the } \\
\text { top of surface } \\
\text { of concrete. }\end{array}$ \\
\hline $\begin{array}{l}\text { Bubble } \\
\text { wrap } \\
\text { plastic }\end{array}$ & moulding & $\begin{array}{l}\text { Bubble wrap } \\
\text { plastic is } \\
\text { placed at the } \\
\text { top of surface } \\
\text { of concrete }\end{array}$ \\
\hline $\begin{array}{l}\text { Plastic \& } \\
\text { stone }\end{array}$ & moulding & $\begin{array}{l}\text { Plastic and } \\
\text { stone are } \\
\text { placed at the } \\
\text { top of half } \\
\text { hardener } \\
\text { concrete, }\end{array}$ \\
\hline $\begin{array}{l}\text { Burned } \\
\text { shaped } \\
\text { Plastic }\end{array}$ & moulding & $\begin{array}{l}\text { Plastic is } \\
\text { placed at the } \\
\text { top of the } \\
\text { concrete }\end{array}$ \\
\hline stone & adding & $\begin{array}{l}\text { Stones are } \\
\text { added in the } \\
\text { concrete cast. }\end{array}$ \\
\hline
\end{tabular}




\begin{tabular}{|l|l|l|}
\hline beads & adding & $\begin{array}{l}\text { Beads are } \\
\text { added in the } \\
\text { concrete cast }\end{array}$ \\
\hline glass & adding & $\begin{array}{l}\text { Glass and } \\
\text { plastic are } \\
\text { added at the } \\
\text { top of the } \\
\text { concrete }\end{array}$ \\
\hline $\begin{array}{l}\text { Natural } \\
\text { Dye }\end{array}$ & dyeing & $\begin{array}{l}\text { The Dye is } \\
\text { mixed with } \\
\text { wet concrete }\end{array}$ \\
\hline
\end{tabular}

\section{Results and Discussion}

Based on several techniques, there are three properties as results from the exploration: texture, colour and light. The first technique, moulding, created two different types of surface, smooth and rough texture. Moulding used plastic material, which has a slick texture, produced a smooth texture on the flat surface. However, in a hollow or curvature field, concrete filled the space so as to create a certain form, hence rough texture. Then, the emphasis on other material, such as stone, on the plastic also provided other form of concrete, which created a valley or hollow on the concrete of the stone and small wrinkles around the hollow that is formed by concrete. The resulting colour of the moulding techniques were bright grey and medium grey. This is because the addition of material above concrete affected the drying process. Thus, this technique is a good process in applying sustainable concrete to the architectural building.

Table 2. The result of moulding technique

\begin{tabular}{|c|c|c|c|}
\hline Result & texture & colour & impact \\
\hline & $\begin{array}{l}\text { Irregular } \\
\text { form with } \\
\text { smooth } \\
\text { surface }\end{array}$ & $\begin{array}{l}\text { Bright } \\
\text { grey }\end{array}$ & $\begin{array}{l}\text { Hollow surface } \\
\text { to provide } \\
\text { living organism }\end{array}$ \\
\hline & $\begin{array}{l}\text { Regular } \\
\text { form with } \\
\text { rough } \\
\text { surface }\end{array}$ & $\begin{array}{l}\text { Medium } \\
\text { grey }\end{array}$ & $\begin{array}{l}\text { shadow at } \\
\text { curvature and } \\
\text { Hollow surface } \\
\text { to provide } \\
\text { living organism }\end{array}$ \\
\hline & $\begin{array}{l}\text { Regular } \\
\text { form with } \\
\text { rough } \\
\text { surface }\end{array}$ & Light grey & $\begin{array}{l}\text { Hollow surface } \\
\text { to provide } \\
\text { living organism }\end{array}$ \\
\hline & $\begin{array}{l}\text { Irregular } \\
\text { form with } \\
\text { rough } \\
\text { surface }\end{array}$ & $\begin{array}{l}\text { Medium } \\
\text { grey }\end{array}$ & $\begin{array}{l}\text { shadow at } \\
\text { irregular form } \\
\text { and hollow } \\
\text { surface } \\
\text { provides living } \\
\text { organism }\end{array}$ \\
\hline
\end{tabular}

\begin{tabular}{|l|l|l|l|}
\hline 4 & $\begin{array}{l}\text { Irregular } \\
\text { form with } \\
\text { rough } \\
\text { surface }\end{array}$ & Light grey & $\begin{array}{l}\text { shadow at } \\
\text { irregular form } \\
\text { and hollow } \\
\text { surface } \\
\text { provides living } \\
\text { organism }\end{array}$ \\
\hline
\end{tabular}

Moreover, all surfaces possess the possibilities in creating an ecological layer above the surface. The hollow that is formed can potentially provide an opportunity for living organisms to live in between concrete. As a result of this moulding process, the surface can reflect the environmental friendly for ecological surrounding by catching the moss or fungus above it. For instance, a bio-enhanced substrate that supports the growth of mosses, lichens, and climbing vegetation, ECOncrete Bio Active ${ }^{[14]}$, is a further development concrete that enhances the surface to support plants with no soil. It has three elements, including concrete chemistry, to capture the moisture that are needed by moss and fungus. This wall can work effectively both as a surface of the façade and the environmental performance of the building.

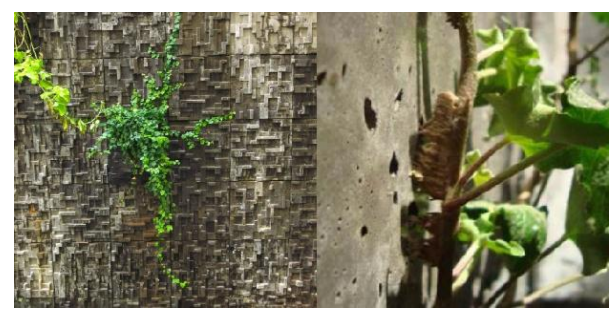

Fig. 7. ECOncrete Bio Active

The second one is adding technique. This technique clearly produces rough texture that is derived from the material added in concrete. However, each material stimulates different qualities on the concrete texture around the added material. For a concrete that is randomly added stone material, the surrounding surface is rougher than the concrete given by the beads due to the layout of the irregular stone, thus the suppressing in concrete and difficult to firm. However, placing the stone as aggregates are commonly used because of its sustainable nature comes from the mining. As for beads and glass, both are rarely materials and often come from the waste of building construction. In the process, these materials are put in regular and irregular placement, made the texture of concrete can still be controlled the level of roughness. One interesting thing about this technique is the addition of colour quality to the concrete derived from additional material, but does not remove the original colour of the concrete. This makes the concrete colour dynamic according to the aggregate material was added. In addition, it is difficult to create an ecological environment for living organism in the result of this concrete because there is no hollow in the surface area. However, the application of stones as the nature materials and beads as the waste materials reflects the sustainability approach in creating the concrete surface. 
Table 3. The result of adding technique

\begin{tabular}{|c|c|c|c|}
\hline Result & texture & colour & impact \\
\hline & $\begin{array}{l}\text { Irregular } \\
\text { form with } \\
\text { rough } \\
\text { surface }\end{array}$ & $\begin{array}{l}\text { Natural } \\
\text { colour from } \\
\text { stone and } \\
\text { medium grey } \\
\text { from } \\
\text { concrete }\end{array}$ & $\begin{array}{l}\text { Durability } \\
\text { of concrete }\end{array}$ \\
\hline & $\begin{array}{l}\text { Irregular } \\
\text { form with } \\
\text { rough } \\
\text { surface }\end{array}$ & $\begin{array}{l}\text { Clear white } \\
\text { beads \& } \\
\text { medium grey } \\
\text { from } \\
\text { concrete }\end{array}$ & $\begin{array}{l}\text { Reused the } \\
\text { waste } \\
\text { material as } \\
\text { concrete }\end{array}$ \\
\hline & $\begin{array}{l}\text { Regular } \\
\text { form with } \\
\text { rough } \\
\text { surface }\end{array}$ & $\begin{array}{l}\text { Coloured } \\
\text { beads \& } \\
\text { medium grey } \\
\text { from } \\
\text { concrete }\end{array}$ & $\begin{array}{l}\text { Reused the } \\
\text { waste } \\
\text { material as } \\
\text { concrete }\end{array}$ \\
\hline & $\begin{array}{l}\text { Irregular } \\
\text { form with } \\
\text { rough } \\
\text { surface }\end{array}$ & $\begin{array}{l}\text { Coloured } \\
\text { glass \& } \\
\text { medium grey } \\
\text { from } \\
\text { concrete }\end{array}$ & $\begin{array}{l}\text { Reused the } \\
\text { waste } \\
\text { material as } \\
\text { concrete }\end{array}$ \\
\hline
\end{tabular}

Finally, the concrete colour on the dye technique, which originally was grey, changed colour as it was mixed in concrete. However, the texture of concrete itself remained in accordance with the moulding surface. one particular point that give benefit in this process is using the natural dye as the addition material of the concrete. Therefore, this makes concrete to be friendly to the environment but still put forward the aesthetic value in its application in architectural buildings.

Table 4. The result of dye technique

\begin{tabular}{|c|c|c|c|}
\hline Result & Texture & colour & light \\
\hline & $\begin{array}{c}\text { Regular } \\
\text { form with } \\
\text { rough } \\
\text { surface }\end{array}$ & $\begin{array}{c}\text { Yellow } \\
\text { and blue } \\
\text { (from } \\
\text { natural } \\
\text { dye) }\end{array}$ & $\begin{array}{c}\text { Non- } \\
\text { reflective }\end{array}$ \\
\hline
\end{tabular}

\section{Conclusions}

The three techniques used; moulding, adding, and dyeing, gave different results in terms of visual qualities. The moulding technique provides maximum texture in both smooth and rough texture as it corresponds to the mould given above the concrete surface. While adding techniques creates another nuance through the shape and colour of the material added in concrete. The effect on the surface of concrete itself is less dominant compared to the additional material. There should be additional treatment to create smooth texture quality in concrete as there is pressure on the concrete while still wet on the proses. In addition, the dyeing technique does not affect the final texture of the concrete.

The moulding technique and the adding technique still shows the colour quality of the concrete material, but they only give different texture to the surface, hence hollow and shadows. The adding technique also provides additional colour quality based on material added to the concrete. Both techniques can possibly give ecological impact in term of applying sustainable concrete on architectural building, including creating a place for living organism to grow at the surface of concrete.

On the other hand, the dyeing technique creates a new look in term of the colour but does not eliminate the quality of concrete in its moulding process. Thus, the dyeing technique can be used as an alternative way to make a sustainable concrete as the final finishing of the building without the painting process. This technique can establish the properties of the concrete material in term of texture while getting additional colour value from the nature material mixed on the liquid cement.

This experiment shall proceed into further development to see the mixed concrete capability as a structure and sculpture, so that the formation of this future surface can be formed along with the building element construction as the architectural design. It is also considered to see the possibilities of living organism to grow in the long term above the surfaces as the impact of the sustainable concrete.

\section{References}

1. A. Picon. Architecture and Technology; Two Centuries of Creative Tension. (2006)

2. J. L. Cohen. G. M. Moeller. Liquid Stone; New Architecture in Concrete. Princeton Architectural Press (2006)

3. B. Palmer. Falling water, Transcending Architecture. (1983)

4. A. Matin. AM House. http://www.andramatin.com/p/am-house/ (2013)

5. A. Loyns. Material for Architects and Builders. (2010)

6. F. Newby. The innovative uses of concrete by engineers and architects, Engrs Structs \& Bldgs, 116 (1996)

7. A. Deplazes. Constructing Architecture; Material Process ; Structures. Birkhauser. 19 (1997)

8. R. Legauth. The Semantic of Exposed Concrete. (2007)

9. P.B Sakthivel. A. Jagannathan. Ferrocement Construction Technology and Application, A Review. (2011)

10. B.N Devikar. Research Needs in Ferrocement Technology. (2011)

11. L. Groat. D. Wang. Architectural Research Method. 322 (2013)

12. T.R Naik. Sustainability of Concrete Construction.

13. I Vinnitskaya. Biological Concrete for a Living, Breathing Façade. https:/www.archdaily.com/315453/biologicalconcrete-for-a-living-breathing-facade . (2013) 
14. Econcrete Bio Active Wall Tile. https://www.mooreconcrete.com/econcrete-bio-active-wall-tile/ (2018) 